\title{
The Effects of Ankaferd Blood Stopper on the Recovery Process in an Experimental Oesophageal Perforation Model
}

\author{
Necla Gürbüz Sarıkaş ${ }^{1}$, Tanzer Korkmaz ${ }^{2}$, Nurettin Kahramansoy ${ }^{3}$, Ali Kılıçgün ${ }^{4}$, Çetin Boran ${ }^{5}$, Güledal Boztaşs \\ ${ }^{1}$ Department of Pediatric Surgery, Derince Training and Research Hospital, Kocaeli, Turkey \\ ${ }^{2}$ Department of Emergency Medicine, Abant İzzet Baysal University Faculty of Medicine, Bolu, Turkey \\ ${ }^{3}$ Department of General Surgery, Abant İzzet Baysal University Faculty of Medicine, Bolu, Turkey \\ ${ }^{4}$ Department of Thoracic Surgery, Abant İzzet Baysal University Faculty of Medicine, Bolu, Turkey \\ ${ }^{5}$ Department of Pathology, Abant İzzet Baysal University Faculty of Medicine, Bolu, Turkey \\ ${ }^{6}$ Province Health Office, Bolu, Turkey
}

Background: Oesophageal perforation is a life-threatening pathology that is generally treated conservatively; however, surgical procedures are frequently performed. A topical haemostatic agent, Ankaferd Blood Stopper (ABS), also has beneficial wound-healing effects.

Aims: This study aimed to determine the effects of ABS following experimental oesophageal perforations. Study Design: Animal experiment.

Methods: The experimental rats were classified into 6 groups (with 7 rats in each group). Pairs of groups (primary repair alone and primary repair $+\mathrm{ABS}$ ) were terminated in the $1^{\text {st }}, 2^{\text {nd }}$, and $3^{\text {rd }}$ weeks following injury. The oesophageal perforations, which were $8-10 \mathrm{~mm}$ in length, were created using a nasogastric tube. The perforation sites were repaired with a 6-0 polyglactine thread in the primary repair groups. Additionally, ABS was sprayed over the perforation site in the treatment groups. Each oesophagus was evaluated histopathologically.
Results: There were fewer microabscesses and areas of necrosis in the ABS groups compared with the primary repair groups. The histopathological evaluation revealed that the ABS groups had less inflammation and more re-epithelisation compared to the primary repair groups $(\mathrm{p}=0.002$ and $\mathrm{p}=0.003$, respectively). Fibrosis in the ABS groups was moderate in the $2^{\text {nd }}$ week and mild in the $3^{\text {rd }}$ week. Comparing the groups with respect to the time intervals, only the $1^{\text {st }}$ week groups showed a significant difference in terms of re-epithelialisation ( $\mathrm{p}=0.044)$.

Conclusion: Topical ABS application on the repaired experimental oesophageal perforation regions led to positive wound-healing effects compared with the rats that were administered the primary repair alone.

Keywords: Ankaferd Blood Stopper, experimental, oesophageal perforation
Oesophageal perforation is a life-threatening condition that is mostly iatrogenic in origin. The causes of oesophageal perforation include spontaneous causes (barogenic and other), foreign bodies, and external trauma (1-4), and the perforation locations are mostly the thoracic, cervical, and abdominal segments, respectively $(2,4)$. Immediately after a perforation, polymicrobial flora, saliva, and various enzymes spread into the mediastinum, causing mediastinitis and empyema (5). Surgical procedures or conservative treatments are the management options. These approaches vary according to the patient characteristics, time of diagnosis, injury type, and perforation severity $(2,4,6)$. Despite these intensive care and advanced

Address for Correspondence: Dr. Necla Gürbüz Sarıkaş, Department of Pediatric Surgery, Derince Training and Research Hospital, Kocaeli, Turkey Phone: +90 5054776445 e-mail: neclagurbuz@yahoo.com

Received: 01.06.2014 Accepted: 28.10.2014 • DOI: 10.5152/balkanmedj.2015.15459

Available at www.balkanmedicaljournal.org 
management procedures, locoregional or systemic complications are frequently observed (2). Locoregional complications, such as anastomotic leakage, wound infection, pleural effusion, mediastinitis, bleeding, and systemic complications, such as sepsis and multiple organ dysfunction syndrome (MODS), lead to high morbidity and mortality rates $(4,5,7,8)$.

Ankaferd Blood Stopper (ABS) is an herbal extract used as a haemostatic agent in traditional Turkish medicine (9). The Turkish Ministry of Health has licensed ABS as a topical haemostasis agent. The pharmacokinetics of the medication remain unclear; however, ABS is clinically used and has been proven to be safe in patients (9). ABS is composed of a standardised mixture of the herbs Thymus vulgaris, Glycyrrhiza glabra, Vitis vinifera, Alpinia officinarum, and Urtica dioica. All of these herbs individually are known to affect the endothelium, blood cells, angiogenesis, cellular reproduction, and vascular dynamics and stimulate mediators that lead to rapidly progressive wound healing (10). Moreover, ABS has antimicrobial activity $(11,12)$.

The aim of this study was to determine the effects of ABS on wound healing following the primary repair of experimental oesophageal perforations and to compare its effects against primary repair alone. The ABS treatments were also anticipated to reduce the complication and mortality frequencies.

\section{MATERIALS AND METHODS}

This study was approved by the University Ethical Committee for Experimental Animal Research. Forty-two male Wistar-Albino rats that weighed 250-300 grams were used. All rats were housed, cared for, and fed in compliance with the related national Guide for the Care and Use of Laboratory Animals legislation. The rats were divided into 6 groups (7 rats in each). Pairs of groups [primary repair (suturing) alone (PR) and primary repair + Ankaferd Blood Stopper (ABS)] were established. The groups were terminated in the $1^{\text {st }}, 2^{\text {nd }}$, and $3^{\text {rd }}$ weeks and were coded as PR1w-ABS1w, PR2w-AB$\mathrm{S} 2 \mathrm{w}$, and PR3w-ABS3w, respectively. The primary end-point was to evaluate the effects of ABS on wound healing, and the secondary end-point was mortality. Anaesthesia was given to the subjects via intramuscular ketamine (Ketalar, Parke DavisEczacıbaşı, İstanbul, Turkey) (50 mg/kg) and xylazine (Rompun, Bayer, Toronto, Canada) (10 mg/kg) administration. Additionally, the rat's necks were shaved and scrubbed with an antiseptic solution. The cervical area of each oesophagus was visualised through a lateral vertical neck incision. A 6 Fr nasogastric tube was inserted into each oesophagus and was used to create a perforation $8-10 \mathrm{~mm}$ in length, according to the model described by Nageris (13). After wiping the blood and saliva away, the perforation site was longitudinally repaired in a single layer with 6-0 polyglactine sutures in both groups. Additionally, the ABS (Ankaferd Blood Stopper spray, Ankaferd Drug Inc., Istanbul, Turkey) was sprayed over the repaired site in the ABS groups. The leakage was then checked by adding isotonic saline from the nasogastric tube. Finally, the neck incisions were anatomically closed using 5-0 polyglactine thread in both groups. The same person performed all operations to ensure standardisation. Neither drains nor antibiotics were used during surgeries or in the follow-up periods.

Oral fluid intake was started 24 hours after the intervention, and solid food intake was started 48 hours following oral fluid intake. After the administration of inhalation anaesthesia with ether, all subjects were sacrificed on the appropriate termination day of the experiment. The peri-oesophageal and thoracic regions were macroscopically evaluated first. Then, each oesophagus was removed, fixed in formalin, embedded in paraffin, sectioned, and stained with haematoxylin-eosin (H\&E) and Gomori trichrome. Notably, a modified histopathological evaluation method was used $(13,14)$. Microabscesses, necrosis and inflammation at the sutured regions, mucosal re-epithelisation, and fibrotic changes were noted. The inflammation, re-epithelisation, and fibrosis parameters were scored on a scale of 0 to 3 (where none $=0$, mild $=1$, moderate $=2$, and complete/severe $=3$ ).

\section{Statistical analysis}

SPSS for Windows (SPSS Inc., Chicago, IL, USA) was used to analyse all data obtained in the study. The statistical differences of the ordinal data (inflammation, re-epithelisation, and fibrosis) between the group pairs were evaluated by using Mann Whitney U tests. Nominal data (microabscess and necrosis) were evaluated by using the Fisher's Exact test. A $\mathrm{p}<0.05$ was defined as a statistically significant value.

\section{RESULTS}

Despite the absence of a conservative therapy (such as antibiotic use), only 3 rats died. The reason for the mortalities was mediastinitis, which progressed after the oesophageal perforation in all of the dead rats. The deaths occurred in 2 of the PR3w group rats and in 1 of the ABS3w group rats. More microabscesses were observed in the PR groups. The microabscess distributions among the $1^{\text {st }}, 2^{\text {nd }}$, and $3^{\text {rd }}$ week PR and ABS groups were $3 / 0,3 / 1$, and $0 / 0$, respectively. Additionally, there were significantly fewer microabscesses in the ABS1w group compared with the PR1w group ( $p=0.046$, Fisher's Exact test).

In the $1^{\text {st }}, 2^{\text {nd }}$, and $3^{\text {rd }}$ week PR and ABS groups, the numbers of rats with necrosis were $0 / 0,2 / 0$ and $3 / 1$, respectively. The paired groups that did not show significant necrosis differenc- 
TABLE 1. Mean histopathological parameter scores and the p-value comparisons of the paired groups. The values in parentheses represent standard error

\begin{tabular}{|c|c|c|c|c|c|c|}
\hline & Inflammation & $\mathrm{p}$ & Reepitelization & $\mathrm{p}$ & Fibrosis & $\mathrm{p}$ \\
\hline PR1w & $2.14(0.34)$ & \multirow{2}{*}{0.061} & $1.71(0.35)$ & \multirow{2}{*}{0.044} & $0.00(0)$ & \multirow{2}{*}{1} \\
\hline ABS1w & $1.28(0.18)$ & & $2.71(0.18)$ & & $0.00(0)$ & \\
\hline PR2w & $2.00(0.37)$ & \multirow{2}{*}{0.096} & $1.00(0.30)$ & \multirow{2}{*}{0.065} & $1.00(0.43)$ & \multirow{2}{*}{0.348} \\
\hline $\mathrm{ABS} 2 \mathrm{w}$ & $1.00(0.43)$ & & $2.14(0.45)$ & & $1.57(0.42)$ & \\
\hline PR3w & $2.40(0.40)$ & \multirow{2}{*}{0.088} & $1.20(0.58)$ & \multirow{2}{*}{0.216} & $2.00(0.44)$ & \multirow{2}{*}{0.555} \\
\hline ABS3w & $1.16(0.16)$ & & $2.16(0.47)$ & & $0.60(0.40)$ & \\
\hline Total PR & $2.21(0.18)$ & 0.002 & $1.31(0.23)$ & 0.003 & $0.53(0.20)$ & 0.116 \\
\hline
\end{tabular}

ABS: Ankaferd blood stopper; PR: primary repair; w: week

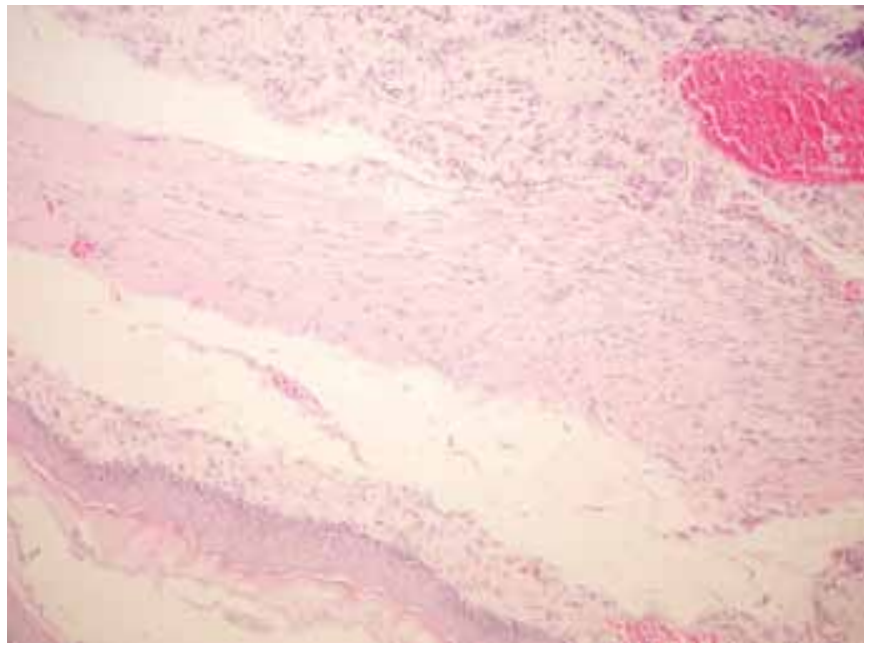

FIG. 1. Early esophageal wall reepithelization in the ABS group at the end of the $1^{\text {st }}$ week (ABS1w, H\&E x 100)

es were the PR2w vs. ABS2w group pair $(\mathrm{p}=0.462)$ and the PR3w vs. ABS3w group pair ( $\mathrm{p}=0.242$, Fisher's Exact test).

Regardless of time, evaluation of the two groups confirmed that the ABS group predominantly presented mild inflammation and that the PR group presented severe inflammation $(\mathrm{p}=0.002)$ (Table 1). Re-epithelialisation was also improved in the ABS group compared to the PR group ( $\mathrm{p}=0.003$ ). Fibrosis was mostly absent or minimal (84.21\%) in the PR group and well progressed in the ABS group at $50 \%$. However, there were no significant differences between the two groups $(\mathrm{p}=0.116)$.

At the end of the $1^{\text {st }}$ week, moderate inflammation was observed in the PR1w group but was mild in the ABS1w group (Table 1). Significantly more re-epithelisation was observed in the ABS1w group compared with the PR1w group ( $\mathrm{p}=0.044)$. However, fibrosis was not observed at the end of the $1^{\text {st }}$ week (Figure 1). The histopathological evaluation parameters are presented in Table 1.

At the end of the $2^{\text {nd }}$ week, less inflammation was observed in the ABS2w group compared with the PR2w group. Additionally, a higher degree of re-epithelisation was also observed

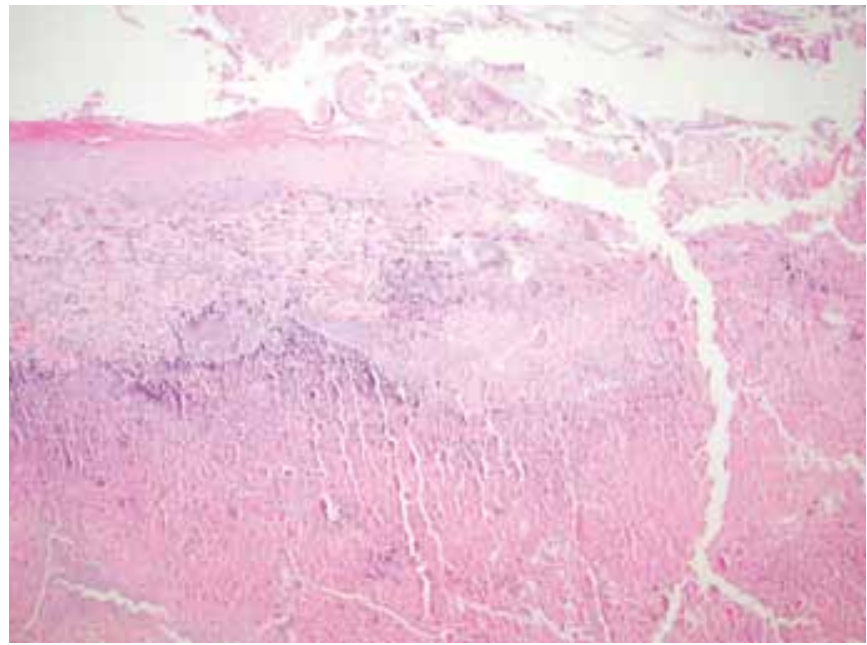

FIG. 2. Necrosis, the intense inflammatory cell infiltration involving the full thickness of the esophageal wall, and the insufficient mucosal reepithelization in the 3-week suturing-only group (PR3w, Gomori trichrome $\times 100$ )

in the ABS2 $w$ group than in the PR2w group. The fibrotic process was moderate in the ABS2 $\mathrm{w}$ group and mild in the PR2w group. However, the differences for each parameter were not significant when the week 2 groups were compared (Figure 2).

At the end of week 3, inflammation was lower in the AB$\mathrm{S} 3 \mathrm{w}$ group compared with the PR3w group, and re-epithelisation was complete in the ABS3w group. Moreover, moderate fibrosis was observed in the PR $3 \mathrm{w}$ group; however, it was reduced in the ABS3w group. There were no significant differences for the parameters (Table 1; Figure 3). Additionally, the complications and frequencies were relatively similar.

\section{DISCUSSION}

A basic, conservative principle in oesophageal perforation treatment is often used to eliminate a septic event. This is achieved by administering broad-spectrum antibiotics, performing nasopharyngeal aspirations, ensuring sufficient pleural drainage, admitting patients to intensive care units, and 


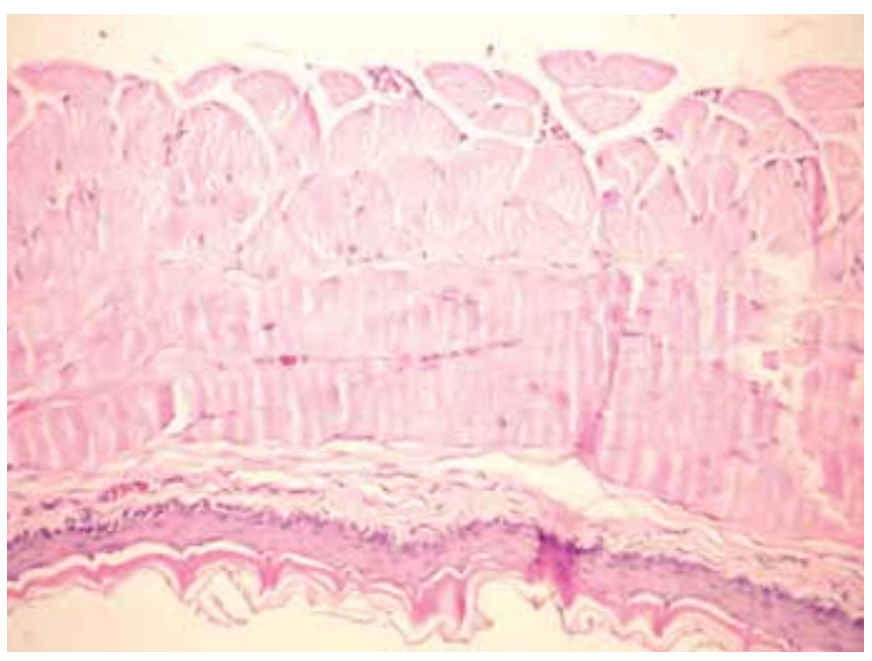

FIG. 3. Mild inflammation and minimal fibrosis in the esophageal wall was observed in the ABS3w group during the $3^{\text {rd }}$ week following injury (H\&E x200)

maintaining adequate nutrition $(5,8,15,16)$. However, major primary repair, resection, and anastomosis surgical procedures are frequently performed. In the last decade, conservative procedures that are accompanied by interventions are increasingly preferred (2). Self-expandable metallic stent placement, endoscopic haemoclipping, and fibrin sealant applications are popular procedures in which some of these applicants need to be removed $(7,16,17)$. Moreover, stenting and clipping have some restrictions, such as causing oesophageal erosion, leak enlargement, fistulae, and stent migration $(18,19)$. Stent applications are unsuccessful in approximately $10 \%$ of patients (19). Laser tissue welding technology has also been used as a transluminal repair method in an animal model (20). This method is fluid-tight and closes the perforation with no foreign substance implantation. However, the method has some disadvantages, as it requires advanced instrumentation and temperature control maintenance. Despite these improvements and new treatment modalities, high complication risks, including anastomotic leakage, wound infection, bleeding, microabscess occurrence, mortality, and others, are ongoing $(4,5,7,8)$. These high complication and mortality rates need to be reduced.

Ankaferd Blood Stopper, a traditional Turkish medicine herbal extract used as a haemostatic agent, is a standardised mixture of the herbs Thymus vulgaris, Glycyrrhiza glabra, Vitis vinifera, Alpinia officinarum, and Urtica dioica (9). ABS is mostly used topically over a wide range of bleeding severities. This agent has also been observed to have pleiotropic cellular effects on the endothelium, blood cells, angiogenesis, cellular reproduction, and vascular dynamics and to stimulate mediators that lead to rapidly progressive wound healing $(10,21)$. Moreover, ABS has antimicrobial activity $(11,12)$. Research- ers have investigated the antimicrobial activity of ABS in various clinical specimens. In agar well diffusion assays, ABS was determined to form wide inhibitory zones for Gram-negative and Gram-positive bacteria, particularly against A. baumanii, methicillin-resistant Staphylococcus aureus, and extendedspectrum b-lactamase $(+)$ E. coli (11). In another study, the overall isolate ratio inhibited by ABS was 92.6\%. Ankaferd was effective against all Enterococcus and Acinetobacter isolates. This result is important, as $90 \%$ of the Enterococcus species and $53.3 \%$ of the Acinetobacter species were inhibited by the control antibiotics vancomycin and imipenem, respectively. Additionally, Ankaferd was also effective against vancomycin-resistant Enterococcus isolates. Ankaferd also exhibited antibacterial activity against clinical methicillin-resistant Staphylococcus aureus isolates (12). Moreover, ABS was also used in an experimental study in an oesophageal caustic injury model. It was observed that oral ABS administration to the rats for 4 weeks produced significantly less inflammation, a lower stenosis index in the oesophagus, and decreased weight loss and mortality in the observed subjects (14).

In this study, fewer microabscesses were detected in the 1and 2-week ABS groups compared with the PR groups, and this difference was statistically significant in the ABS1w and PR1w group comparison. A lower (but not significant) level of necrosis was also observed in the $2^{\text {nd }}$ and $3^{\text {rd }}$ week ABS groups compared with the PR groups. Therefore, these data suggest that ABS has antimicrobial effects and that using ABS in patients with oesophageal perforations might allow a shortened duration of antimicrobial therapy. Additionally, although the difference was not significant, inflammation was less severe in the ABS groups compared with the PR groups. Fibrosis, a component of the wound-healing process, was slightly increased in the ABS2w group and slightly decreased in the AB$\mathrm{S} 3 \mathrm{w}$ group compared with the PR2w and the PR3w groups, respectively. Moreover, re-epithelisation progressed well in the ABS groups, especially in the ABS1w group compared with the PR1w group. These histopathological results demonstrate that ABS has beneficial inflammation and wound-healing effects. Although these effects were limited, we anticipate that ABS might prevent complications and oesophageal healing restrictions.

In conclusion, ABS has anti-inflammatory and positive wound-healing effects following operative oesophageal perforation procedures. ABS can be applied easily and topically with no risk. However, its effects seem to be limited, and further experimental and clinical studies are needed to evaluate its effects with regard to operative procedures and conservative oesophageal perforation treatments.

Ethics Committee Approval: Ethics committee approval was received from Abant İzzet Baysal University Hospital. 


\section{Informed Consent: N/A.}

Peer-review: Externally peer-reviewed.

Author contributions: Concept - N.G.S.; Design - N.G.S.; Supervision - N.G.S., T.K.; Resource - N.G.S., A.K., N.K.; Materials - N.G.S., T.K., A.K., N.K.; Data Collection\&/or Processing - G.B., N.G.S.; Analysis\&/or Interpretation - G.B., N.G.S., Ç.B.; Literature Search - N.G.S., T.K.; Writing - N.G.S., N.K.; Critical Reviews N.K., N.G.S.

Acknowledgements: The authors are thankful to associate Professor MD Nurettin Kahramansoy for providing support in writing of this study.

Conflict of Interest: No conflict of interest was declared by the authors.

Financial Disclosure: The authors declared that this study has received no financial support.

\section{REFERENCES}

1. Wu JT, Mattox KL, Wall MJ Jr. Esophageal perforations: new perspectives and treatment paradigms. J Trauma 2007;63:117384. [CrossRef]

2. Kuppusamy MK, Hubka M, Felisky CD, Carrott P, Kline EM, Koehler RP, et al. Evolving management strategies in esophageal perforation: surgeons using nonoperative techniques to improve outcomes. J Am Coll Surg 2011;213:164-71. [CrossRef]

3. Okten I, Cangir AK, Ozdemir N, Kavukçu S, Akay H, Yavuzer S. Management of esophageal perforation. Surg Today 2001;31:36-9. [CrossRef]

4. Eroglu A, Turkyilmaz A, Aydin Y, Yekeler E, Karaoglanoglu N. Current management of esophageal perforation: 20 years experience. Dis Esophagus 2009;22:374-80. [CrossRef]

5. Martinez L, Rivas S, Hernández F, Avila LF, Lassaletta L, Murcia J, et al. Aggressive conservative treatment of esophageal perforations in children. J Pediatr Surg 2003;38:685-9. [CrossRef]

6. Sepesi B, Raymond DP, Peters JH. Esophageal perforation: surgical, endoscopic and medical management strategies. Curr Opin Gastroenterol 2010;26:379-83. [CrossRef]

7. Erdogan A, Gurses G, Keskin H, Demircan A. The sealing effect of a fibrin tissue patch on the esophageal perforation area in primary repair. World J Surg 2007;31:2199-2203. [CrossRef]

8. Demirbag S, Tiryaki T, Atabek C, Surer I, Ozturk H, Cetinkursun $\mathrm{S}$. Conservative approach to the mediastinitis in childhood secondary to esophageal perforation. Clin Pediatr (Phila) 2005;44:131-4. [CrossRef]
9. Goker H, Haznedaroglu IC, Ercetin S, Kirazli S, Akman U, Ozturk Y, et al. Haemostatic actions of the folkloric medicinal plant extract Ankaferd Blood Stopper. J Int Med Res 2008;36:163-70. [CrossRef]

10. Bilgili H, Kosar A, Kurt M, Onal IK, Goker H, Captug O, et al. Hemostatic efficacy of Ankaferd Blood Stopper in a swine bleeding model. Med Princ Pract 2009;18:165-9. [CrossRef]

11. Tasdelen Fisgin N, Tanriverdi Cayci Y, Coban AY, Ozatli D, Tanyel E, Durupinar B, et al. Antimicrobial activity of plant extract Ankaferd Blood Stopper. Fitoterapia 2009;80:48-50. [CrossRef]

12. Saribas Z, Sener B, Haznedaroglu IC, Hascelik G, Kirazli Ş, Goker H. Antimicrobial activity of Ankaferd Blood Stopper against nosocomial bacterial pathogens. Cent Eur J Med 2010;5:198-202. [CrossRef]

13. Nageris BI, Zilker Z, Zilker M, Kariv N, Feinmesser R, Katzir A. Esophageal incisions repair by $\mathrm{CO} 2$ laser soldering. Otolaryngol Head Neck Surg 2004;131:856-9. [CrossRef]

14. Akbal E, Köklü S, Karaca G, Astarci HM, Koçak E, Taş A, et al. Beneficial effects of Ankaferd Blood Stopper on caustic esophageal injuries: an experimental model. Dis Esophagus 2012;25:188-94. [CrossRef]

15. Gander JW, Berdon WE, Cowles RA. Iatrogenic esophageal perforation in children. Pediatr Surg Int 2009;25:395-401. [CrossRef]

16. Leers JM, Vivaldi C, Schäfer H, Bludau M, Brabender J, Lurje $\mathrm{G}$, et al. Endoscopic therapy for esophageal perforation or anastomotic leak with a self-expandable metallic stent. Surg Endosc 2009;23:2258-2262. [CrossRef]

17. Fischer A, Schrag HJ, Goos M, von Dobschuetz E, Hopt UT. Nonoperative treatment of four esophageal perforations with hemostatic clips. Dis Esophagus 2007;20:444-8. [CrossRef]

18. Freeman RK, Ascioti AJ, Giannini T, Mahidhara RJ. Analysis of unsuccessful esophageal stent placements for esophageal perforation, fistula, or anastomotic leak. Ann Thorac Surg 2012;94:959-65. [CrossRef]

19. D'Cunha J, Rueth NM, Groth SS, Maddaus MA, Andrade RS. Esophageal stents for anastomotic leaks and perforations. J Thorac Cardiovasc Surg 2011;142:39-46.e1.

20. Bleier BS, Gratton MA, Leibowitz JM, Palmer JN, Newman JG, Cohen NA. Laser-welded endoscopic endoluminal repair of iatrogenic esophageal perforation: an animal model. Otolaryngol Head Neck Surg 2008;139:713-7. [CrossRef]

21. Haznedaroglu BZ, Beyazit Y, Walker SL, Haznedaroglu IC. Pleiotropic cellular, hemostatic, and biological actions of Ankaferd hemostat. Crit Rev Oncol Hematol 2012;83:21-34. [CrossRef] 